\title{
PENGARUH PEMBELAJARAN PKn TERHADAP PENGEMBANGAN \\ SIKAP NASIONALISME SISWA KELAS VII SEMESTER GENAP \\ SMP NEGERI 2 BARAT KECAMATAN BARAT KABUPATEN \\ MAGETAN \\ TAHUN PELAJARAN 2014/2015
}

\author{
Soenarjo* \\ Wawan Kokotiasa $^{* *}$ \\ Johan Satria Wicaksana $^{* * *}$
}

\begin{abstract}
Abstrak
$\mathrm{P}$

enelitian ini bertujuan untuk mengetahui pengaruh pembelajaran PKn terhadap sikap nasionalisme siswa kelas VII Semester Genap SMP Negeri ini, populasi yang diambil berjumlah 210 siswa sehingga diperoleh sampel berjumlah 80 siswa. Pengumpulan data pada penelitian ini menggunakan angket. Analisis data menggunakan teknik koefisiensi korelasi yaitu koefisiensi product moment. Hasilnya menunjukkan dari hasil penghitungan koefisien korelasi diperoleh $r^{2}=0,97^{2}=0,94$. Hal ini menyatakan bahwa sikap nasionalisme dipengaruhi oleh pembelajaran PKn sebesar 4\%, sisanya 96\% dipengaruhi oleh faktor lain.

Sedangkan hasil analisis data berdasarkan penghitungan dengan menggunakan persamaan regresi ditemukan harga $a=-1,98$ dan harga $b=1,11$, persamaan regresinya yaitu $\hat{Y}=-1,98+1,11 \mathrm{X}$. . Hasil dari koefisien $b$ menunjukkan angka positif, berarti apabila nilai atau harga $\mathrm{X}$ pada variabel pembelajaran PKn naik, sikap nasionalisme juga akan naik. Hasil tersebut menunjukkan bahwa ada pengaruh antara pembelajaran PKn terhadap sikap nasionalisme.
\end{abstract}

Kata Kunci: Pembelajaran PKn, Sikap Nasionalisme

\footnotetext{
* Dosen Prodi PPKn IKIP PGRI Madiun

** Dosen Prodi PPKn IKIP PGRI Madiun

**** Mahasiswa Prodi PPKn IKIP PGRI Madiun
} 
PENDAHULUAN

Perjalanan panjang sejarah bangsa Indonesia yang dimulai sejak era dan sebelum penjajahan, kemudian dilanjutkan dengan era perebutan dan mempertahankan kemerdekaan sampai era pengisian kemerdekaan menimbulkan kondisi dan tuntutan yang berbeda sesuai dengan zamannya. Kondisi dan tuntutan yang berbeda tersebut ditanggapi oleh bangsa Indonesia berdasarkan kesamaan nilai-nilai perjuangan bangsa yang senantiasa tumbuh dan berkembang. Kesamaan nilai-nilai ini dilandasi oleh jiwa, tekad, dan semangat kebangsaan. Semua itu tumbuh menjadi kekuatan yang mampu mendorong proses terwujudnya Negara Kesatuan Republik Indonesia.

Semangat perjuangan bangsa merupakan kekuatan mental dan spriritual yang dapat melahirkan sikap dan perilaku heroik, patriotik dan menumbuhkan semangat nasionalisme. Semangat perjuangan bangsa inilah yang harus dimiliki oleh setiap warga negara untuk mempertahankan dan berpartisipasi mengisi kemerdekaan. Dalam dinamika kehidupan, masyarakat

telah mengalami penurunan pada titik yang kritis dalam mempertahankan dan mengisi kemerdekaan. Hal ini disebabkan oleh pengaruh globalisasi yang ditandai olehpengaruh budaya internasional. Globalisai juga ditandai oleh pesatnya perkembangan ilmu pengetahuan dan teknologi, khususnya di bidang informasi, komunikasi. Hal ini membuat dunia seolah olah menjadi kampung tanpa mengenal batas negara. Kondisi ini akan mempengaruhi struktur dalam kehidupan bermasyarakat, berbangsa dan bernegara di Indonesia, serta akan mempengaruhi pola pikir, sikap, dan tindakan masyarakat Indonesia. Pada akhirnya kondisi tersebut akan mempengaruhi kondisi mental spiritual bangsa.

Upaya untuk mengatasi
masalah $\begin{aligned} & \text { tersebut } \\ & \text { melalui }\end{aligned}$
pembentukan dan peningkatan rasa
dan semangat nasionalisme di
seluruh lapisan masyarakat
Indonesia. Melalui rasa dan
semangat nasionalisme $r$ ini,
diharapkan timbul untuk membela
kepentingan negara di atas
kepentingan


peningkatan rasa nasionalisme, diharapkan masyarakat Indonesia dapat mencerminkan sikap cinta tanah air dan rasa nasionalisme. Upaya untuk mencapai tujuan tersebut antara lain melalui pendidikan formal.

Hal itu sejalan dengan sistem pendidikan nasional. Berdasarkan Undang-Undang Nomor 20 tahun 2003 tentang Sistem Pendidikan Nasional bahwa Pendidikan nasional berfungsi mengembangkan kemampuan dan membentuk watak serta peradaban bangsa yang bermartabat dalam rangka mencerdaskan kehidupan bangsa, bertujuan untuk berkembangnya potensi peserta didik agar menjadi manusia yang beriman dan bertakwa kepada Tuhan Yang Maha Esa, berakhlak mulia, sehat, berilmu, cakap, kreatif, mandiri, dan menjadi warga negara yang demokratis serta bertanggung jawab.

Permasalahan yang dihadapi dalam berlangsungnya pendidikan adalah kurangnya makna dan pembentukan semangat nasionalisme siswa yang mengakibatkan lunturnya kesadaran akan makna dari kebangsaan sebagai bangsa Indonesia. Jika hal ini dibiarkan, lunturnya semangat nasionalisme pada siswa akan berdampak buruk dalam dinamika kehidupan bermasyarakat, berbangsa, dan bernegara. Dengan adanya permasalahan tersebut, dalam pembelajaran Pendidikan Pancasila dan Kewarganegaraan harus dapat menumbuhkan jiwa untuk mempertebal rasa nasionalisme dan meningkatkan wawasan kebangsaan siswa. Isnani Murti (2008: 3) menyatakan bahwa rasa kebangsaan atau wawasan kebangsaan merupakan salah satu bentuk rasa cinta tanah air yang melahirkan jiwa kebersamaan untuk satu tujuan yang sama. Wawasan kebangsaan adalah cara pandang yang dilingkupi oleh rasa kebangsaan, paham kebangsaan dan semangat kebangsaan untuk mencapai cita-cita nasionalnya dan mengembangkan eksistensi kehidupannya atas dasar nilai-nilai luhur bangsa. Implementasi dan akualisasinya dari berbagai hal yang erat kaitannya dengan pemikiran yang menyangkut aspek kehidupan ideologi, politik, ekonomi, sosial, budaya, hukum dan hankam, untuk 
membawa bangsa ke arah kehidupan yang lebih maju dan baik.

Undang-Undang Nomor 20

Tahun 2003, menyatakan bahwa pendidikan nasional adalah pendidikan yang berdasarkan Pancasila dan Undang-Undang Dasar 1945. Hal ini dapat dikatakan sebagai "wahana utama untuk memelihara serta menumbuhkan semangat kebangsaan karena pranata dan institusi pendidikan pada hakikatnya merupakan kekuatan pembangkit gerakan watak semangat kebangsaan". Adanya pelaksanaan pengajaran pendidikan kewarganegaraan diharapkan dapat memberi peran bagi pembentukan semangat nasionalisme. Pendidikan kewarganegaraan dapat membentuk warga negara yang baik, yaitu warga negara yang sanggup melaksanakan hak dan kewajibannya dalam kehidupan berbangsa dan bernegara dan mampu mengutamakan kepentingan negara di atas kepentingan pribadi dan kelompok.

Berdasarkan hasil observasi yang dilakukan di SMP Negeri 2 Barat Kabupaten Magetan, pada kelas VII Semester Genap Tahun Pelajaran 2014/2015, terlihat bahwa semangat nasionalisme siswa di sekolah mulai berkurang. Dari pengamatan yang dilakukan,ditemukan siswa yang bersembunyi di dalam sekolah atau di tempat parkir sepeda belakang sekolah pada saat upacara bendera setiap Senin dan upacara peringatan hari kemerdekaan Republik Indonesia 17 Agustus 1945. Selain itu, para siswa lebih menghapal tokoh kartun dan lagu Korea dibandingkan dengan tokoh pahlawan Indonesia dan lagu wajib Negara Kesatuan Republik Indonesia. Saat siswa di konfirmasi mengenai budaya asli Negara Kesatuan Republik Indonesia, siswa cenderung bersikap acuh dan tidak peduli.Para siswa cenderung lebih memilih budaya yang ada sekarang daripada nilai-nilai perjuangan bangsa yang sudah ada sejak dulu.

Pendidikan Kewarganegaraan dalam pengertiannya sebagai civic education dan citizenship education. Civic education dapat diartikan sebagai suatu pelajaran yang dirancang untuk mempersiapkan para generasi muda agar mampu berperan aktif dalam masyarakat. Citizenship education mempunyai arti yang lebih 
luas, yang mencakup formal dan informal.

Pendidikan

kewarganegaraan dapat juga disebut civic education yang artinya suatu program pendidikan yang merupakan perkembangan dan perluasan dari ilmu kewarganegaraan yang berfokus pada perluasan demokrasi politik, demokrasi sosial, dan demokrasi ekonomi dengan pengaruh positif dari pendidikan sekolah, keluarga dan masyarakat (Parji, 2010: 2).

Berkaitan dengan perlunya peningkatan semangat nasionalisme siswa melalui jalur pendidikan yaitu melalui pembelajaran pendidikan kewarganegaraan tersebut, maka dilakukan suatu pembahasan tentang: Pengaruh Pembelajaran PKn Terhadap Pengembangan Sikap Nasionalisme Siswa kelas VII SMP Negeri 2 Barat Semester Genap Tahun Pelajaran 2014/2015.

\section{METODE PENELITIAN}

Populasi berjumlah 210 siswa dengan sampel 80 siswa. Pengumpulan data menggunakan angket tentang pembelajaran PKn dan sikap nasionalisme. Teknik koefisiensi korelasi yang digunakan adalah koefisiensi product moment dengan rumus:

$$
r_{x y}=\frac{x y}{x^{2} y^{2}}
$$

Keterangan:

$\mathrm{r}_{x y}=$ Korelasi antara variabel $\mathrm{X}$

dengan $\mathrm{Y}$

$\mathrm{x}=$ Variabel independen

(Pembelajaran

PKn)

$\mathrm{y}=$ Variabel dependen (Sikap

Nasionalisme siswa)

Hasil dari korelasi

dibandingkan dengan harga product moment diantara taraf signifikasi 1 $\%$ dan $5 \%$ yang mendekati untuk ditarik kesimpulan mengenai ada tidaknya pengaruh.

Sedangkan untuk mengetahui linieritas variable $\mathrm{X}$ terhadap $\mathrm{Y}$ digunakan analisis regresi dengan persamaan : $\hat{Y}=a+b X$.

\section{HASIL DAN PEMBAHASAN}

Deskripsi pembelajaran PKn dengan menggunakan angket yang telah diberikan kepada 80 siswa dapat diperoleh data sebagai berikut :

a) jumlah skor total $=3922$, b) Ratarata $=49,03$, c) Modus $=49,5$. d) Median $=48,86$, dan e) Standar deviasi sebesar 5,73. 
Dari deskripsi di atas, setelah dianalisis menunjukkan bahwa dari 80 siswa yang mendapatkan nilai di atas rata-rata $(>49,03)$ sebanyak 31 orang atau 38,75\%, dan 49 orang atau $61,25 \%$ yang mendapat angka di bawah rata-rata. Artinya siswa dalam mengikuti pembelajaran PKn siswa terkesan masih kurang bersemangat.

Deskripsi sikap nasionalisme dengan menggunakan angket yang telah diberikan kepada 80 siswa dapat dideskripsikan : a) jumlah skor total $=4161$, b) Rata-rata $=52,01, \mathrm{c}$ ) Modus $=49$, d) Median $=51,94$, dan e) Standar deviasi sebesar 6,54.

Dari deskripsi di atas, setelah dianalisis menunjukkan bahwa dari 80 siswa yang mendapatkan nilai di atas rata-rata(> 52,01) sebanyak 36 orang atau $45 \%$, dan 44 orang atau $55 \%$ yang mendapat angka di bawah rata-rata. Artinya sikap nasionalisme siswa pada pembelajaran Pkn secara umum masih di bawah rata-rata.

Untuk keperluan pengelompokkan hasil angket dari sampel tentang pelaksanaan pembelajaran ditetapkan menjadi lima kelas/interval yaitu sangat baik, baik, cukup, kutang dan sangat kurang. Rumus yang digunakan untuk menentukan lebar interval(i) adalah jarak pengukuran(R) dibagi jumlah kelas.

$$
\begin{aligned}
& i=R / k \\
R \quad= & N \max -N \min \\
= & 64-36 \\
= & 28 .
\end{aligned}
$$

Jadi lebar kelas(i) $=28: 5=5,6$

Dari pengelompokkan tersebut disajikan hasil angket pembelajaran PKn sebagaimana tercantum pada table 2 berikut.

Tabel 2.Interval Kelas Hasil Angket Mengenai Pembelajaran PKN Kelas VII SMPN 2 Barat Tahun Pelajaran $2014 / 2015$.

\begin{tabular}{|c|c|c|c|c|}
\hline No & $\begin{array}{c}\text { Nilai } \\
\text { Interval }\end{array}$ & Kategori & F & $\begin{array}{c}\text { Prosen } \\
\text {-tase } \%\end{array}$ \\
\hline 1 & $59-64$ & Sangat Baik & 7 & 8,75 \\
\hline 2 & $54-58$ & Baik & 13 & 16,25 \\
\hline 3 & $48-53$ & Cukup & 31 & 38,75 \\
\hline 4 & $41-47$ & Kurang & 23 & 28,75 \\
\hline 5 & $36-41$ & $\begin{array}{c}\text { Sangat } \\
\text { Kurang }\end{array}$ & 7 & $8,75 \%$ \\
\hline \multicolumn{5}{|c|}{ Jumlah perdasarkan penghitungan } \\
\hline
\end{tabular}

data di atas, dapat dikatakan bahwa pembelajaran PKN siswa kelas VII SMP Negeri 2 Barat Semester Genap Tahun Pelajaran 2014/2015 sedang. Hal ini terbukti dari 80 siswa ada $8,75 \%$ berkategori sangat baik, 
$16,25 \%$ berkategori baik, $37,25 \%$ berkategori cukup, $28,75 \%$ berkategori kurang, dan 8,75\% berkategori sangat kurang.

\section{Untuk keperluan}

pengelompokkan hasil angket dari sampel tentang sikap nasionalisme siswa ditetapkan menjadi lima kelas/interval yaitu sangat baik, baik, cukup, kutang dan sangat kurang. Rumus yang digunakan untuk menentukan lebar interval(i) adalah jarak pengukuran(R) dibagi jumlah kelas.

$$
\begin{aligned}
& i=R / k \\
R \quad= & N \max -N \min \\
= & 66-36 \\
= & 30 .
\end{aligned}
$$

Jadi lebar $\operatorname{kelas}(i)=30: 5=6$

Dari pengelompokkan tersebut disajikan hasil angket sikap nasionalisme sebagaimana tercantum pada table 3 berikut.

\begin{tabular}{|c|c|c|c|c|}
\hline 5 & $46-50$ & Sangat Kurang & 4 & 5 \\
\hline \multicolumn{3}{|c|}{ Jumlah } & 80 & 100 \\
\hline
\end{tabular}

Tabel 3.Interval Kelas Hasil Angket

Mengenai Sikap Nasionalisme Siswa

$$
\text { Kelas VII }
$$

Berdasarkan penghitungan data di atas, dapat dikatakan bahwa sikap nasionalisme siswa kelas VII SMP Negeri 2 Barat Semester Genap Tahun Pelajaran 2014/2015 adalah kurang. Hal ini terbukti dari 80 siswa ada $16,25 \%$ berkategori sangat baik, $25 \%$ berkategori baik, $33,75 \%$ berkategori cukup, $20 \%$ berkategori kurang, dan 5\% berkategori sangat kurang.

Untuk mencari hubungan antara pembelajaran PKN terhadap sikap nasionalisme digunakan korelasi product moment.

$$
\begin{array}{r}
\text { xy }=2.894 \\
x^{2}=2.628 \\
y^{2}=3.419 \\
r_{x y}=\frac{\text { xy }}{x^{2} y^{2}} \\
r_{x y}=\frac{\text { xy }}{x^{2} y^{2}} \\
r_{x y}=\frac{2894}{\frac{26283419}{2634}}
\end{array}
$$

SMPN 2 Barat Tahun Pelajaran

2014/2015.

\begin{tabular}{|c|c|c|c|c|}
\hline No & $\begin{array}{c}\text { Nilai } \\
\text { Interval }\end{array}$ & Kategori & F & $\begin{array}{c}\text { Prosen- } \\
\text { tase } \%\end{array}$ \\
\hline 1 & $60-66$ & Sangat Baik & 13 & 16,25 \\
\hline 2 & $61-65$ & Baik & 20 & 25 \\
\hline 3 & $56-60$ & Cukup & 27 & 33.75 \\
\hline 4 & $51-55$ & Kurang & 16 & 20 \\
\hline
\end{tabular}

$$
\begin{aligned}
& r_{x y}=\frac{2894}{\overline{8985132}} \\
& r_{x y}=\frac{2894}{2997,52} \\
& r_{x y}=0,97
\end{aligned}
$$


Hal tersebut menunjukkan

hubungan pembelajaran PKN terhadap sikap nasionalisme sangat kuat.

Sedangkan untuk mengetahui linieritas variable $\mathrm{X}$ terhadap $\mathrm{Y}$ digunakan analisis regresi. Berdasarkan penghitungan data yang ada, diperoleh:

$$
\begin{aligned}
\mathrm{N} & =80 \\
\sum \mathrm{X} & =3922 \\
\sum \mathrm{Y} & =4161 \\
\sum \mathrm{X}^{2} & =194904 \\
\sum \mathrm{Y}^{2} & =219843 \\
\sum \mathrm{XY} & =206.887
\end{aligned}
$$

Untuk memperoleh nilai a dibutuhkan rumus sebagai berikut.

$$
\begin{aligned}
& a=\frac{Y)\left(\sum X^{2}-\left(\sum X\right)\left(\sum X Y\right)\right.}{n \sum X^{2}-\left(\sum X\right)^{2}} \\
& a=\frac{4161(194904)-3922(205528)}{80(194904)-(3922)^{2}} \\
& a=\frac{810995544-811410814}{15592320-15382084} \\
& a=\frac{-415270}{210236} \\
& a=-1,98
\end{aligned}
$$

Selanjutnya ialah mencari nilai koefisiensi b, nilai koefisiensi dari data di atas sebagai berikut.

$$
\mathrm{b}=\frac{80(206887)-(3922)(4161)}{80(194904)-(3922)^{2}}
$$

$$
\mathrm{b}=\frac{80(206887)-(3922)(4161)}{80(194904)-(3922)^{2}}
$$

$$
\mathrm{b}=\frac{16550960-16319442}{15592320-15382084}
$$

$\mathrm{b}=\frac{231518}{210236}$

$\mathrm{b}=1,11$

Selanjutnya memasukkan nilai-nilai tersebut ke dalam rumus persamaan regresi $\hat{Y}=a+b X$.

$$
\begin{aligned}
& \hat{Y}=a+b X \\
& \hat{Y}=-1,98+1,11 X .
\end{aligned}
$$

Koefisien $b$ disebut sebagai koefisien arah regresi linier dan menyatakan perubahan rata-rata variabel Y untuk setiap perubahan variabel $\mathrm{X}$ sebesar nilai satu unit. Perubahan ini menunjukkan pertambahan nilai karena $b$ bertanda positif. Hasil penghitungan, diperoleh $\mathrm{b}=1,11$ bertanda positif. Artinya, setiap kali variabel $\mathrm{X}$ (pembelajaran PKN) bertambah satu maka rata-rata variabel Y (sikap nasionalisme) bertambah 1,11. Jadi, ada pengaruh antara pembelajaran 
PKN terhadap sikap nasionalisme siswa kelas VII SMP Negeri 2 Barat Semester Genap Tahun Pelajaran 2014/2015.

\section{KESIMPULAN}

Berdasarkan pembahasan di atas, dapat disimpulkan bahwa kategori pembelajaran $\mathrm{PKn}$ kelas VIII SMP Negeri 2 Barat Semester Genap Tahun Pelajaran 2014/2015 adalah sedang. Hal ini terbukti dari 80 siswa ada $8,75 \%$ berkategori sangat baik, 16,25\% berkategori baik, 37,25 \% berkategori cukup, $28,75 \%$ berkategori kurang, 20\% berkategori kurang, dan $8,75 \%$ berkategori sangat kurang. Sikap nasionalisme siswa kelas VII SMP Negeri 2 Barat Semester Genap Tahun Pelajaran 2014/2015 adalah kurang.

Berdasarkan penghitungan data dapat disimpulkan bahwa sikap nasionalisme 80 siswa ada $16,25 \%$ berkategori sangat baik, $25 \%$ berkategori baik, 33,75\% berkategori cukup, ,20\% berkategori kurang, dan $5 \%$ berkategori sangat kurang.

Ada pengaruh antara pembelajaran PKn terhadap pengembangan sikap nasionalisme.
Pengujian hipotesis menggunakan rumus $r$ product moment diperoleh koefisien korelasi sebesar $0,97^{2}=$ 0,94 yang berarti ada hubungan positif antara pembelajaran PKn terhadap sikap nasionalisme siswa kelas VII SMP Negeri 2 Barat Semester Genap Tahun Pelajaran 2014/2015. Sedangkan berdasarkan linieritas diperoleh persamaan regresi:

$$
\hat{\mathrm{Y}}=-1,98+1,11 \mathrm{X} .
$$

Hal ini terbukti walaupun kecil(hanya 1,11), sikap nasionalisme dipengaruhi oleh pembelajaran PKn sedangkan sisanya dipengaruhi oleh faktor lain. 


\section{DAFTAR PUSTAKA}

Husaini Usman. 2006. Pengantar Statistika. Jakarta: Bumi Aksara

Ine Kusuma \& Markum Susatim. 2010. Pendidikan

Kewarganegaraan Berbasis Nilai. Bogor: Ghalia Indonesia.

Isnani Murti. 2008. Jurnal Pendidikan . Bandung: Pustaka Pelajar

Kasan Juwair. 2008. Penanaman nilai-nilai Nasionalisme Pada Proses Belajar Mengajar $P K n$. Semarang: Angkasa cipta

Komaruddin Hidayat dan Azyumardi Azra. 2008. Demokrasi Hak Asasi Manusia Dan Masyarakat Madani. Jakarta: Kencana

Sugiyono. 2012. Metode Penelitian Kuantitatif Kualitatif dan $R \& D$. Bandung: Alfabeta

Suharsini Arikunto. 2010. Prosedur Penelitian. Jakarta: PT Rineka Cipta

Sumarsono. 2001. Pendidikan Kewarganegaraan. Jakarta: Gramedia Pustaka Utama

Tilaar. 2004.Multikulturalisme. Jakarta: Grasindo

Undang-Undang Republik Indonesia No.20 Tahun 2003 Tentang Sistem Pendidikan Nasional. 2003. Jakarta: PT Armas Duta
Parji. 2010. Pendidikan

Kewarganegaraan. Magetan:

Swastika press. 